\title{
The impact of a computerized care records service (CRS) on doctors' work patterns in urological outpatient clinics
}

\author{
Stefanos Kachrilas, Christian Bach, Pryia Kumar, Faruqz Zaman, Nicola Dickens, \\ Junaid Masood, Noor Buchholz*
}

Endourology \& Stone Services, Department of Urology, Barts and The London NHS Trust, London, United Kingdom;

${ }^{*}$ Corresponding Author: noor.buchholz@gmail.com

Received 18 August 2011; revised 13 October 2011; accepted 21 October 2011.

\begin{abstract}
Objective: Government targets to reduce waiting times are putting enormous pressures on outpatient services. The implementation of an electronic care records service (CRS) at our hospital in 2008 has led to widespread press coverage of ensuing chaos in clinical administration. We wanted to know how this new electronic system impacted on our working patterns in outpatient clinics and-more specifically-on the time actually spent with the patients. Material \& methods: This study was performed 4 and 12 months after implementation of CRS to assess its impact on the time distribution in clinic. Senior doctors were monitored with a stop clock during consultations. Timings for pre- and post-consultation administration, and the actual consultation with the patient were recorded. A total of $\mathbf{1 7 0}$ consultations were evaluated in this way. Results: The key findings were that the total time needed to spend on a urological outpatient of 16 minutes remains unchanged from the pre-CRS era, but a majority (57\%) of this time is spent in administration on the computer without the patient involved. Conclusion: No more than 15 patients should be seen in a 4 hour outpatient clinic per doctor. This recommendation drawn up by BAUS before CRS remains still valid. Patient administration related to the consultation that has previously been done by administrative aides is now to be done by the doctors on the computer in the same consultation session. Intended to streamline patient pathways, this does reduce the quality interaction-time between doctor and patients significantly.
\end{abstract}

Keywords: Working Pattern; Consultation Time; care records service; Outpatient Clinic; National Health System NHS

\section{INTRODUCTION}

Just before the end of the $20^{\text {th }}$ century, an outlook on the future of British Urology concluded that the urological workload was set to increase. This was thought to be mainly due to an increase in screening, investigations, counselling and non-surgical treatments [1]. All these activities concern the work in outpatient clinics. More recently, government initiatives to improve patient care and reduce waiting times have added even more pressures on the effective use of outpatient resources [2]. Indeed, only around $20 \%$ of urologists are able to follow recommendations of the British Association of Urological Surgeons (BAUS) for outpatient workload "A Quality Urological Service for Patients in the new Millenium" published in 2000 [3,4]. The average urology consultant team in the United Kingdom (UK) "overperfoms" in outpatient clinics by a factor of 1.4 [4]. Consultants do spend more time with patients than in the past. The list of medical investigations and surgical treatments has increased dramatically, and patients are better informed, more demanding and expect more explanation, with doctors increasingly offering to share their knowledge [1,5]. Therefore, it was thought that perhaps an electronic system to access and record patient information may be the best approach to ease these pressures [6].

As one of a handful of sites, the Care Record Service (CRS) by Cerner was implemented at Barts and The London NHS Trust in April 2008 as part of a $£ 12.7$ billion National Program for Information Technology (IT) in the National Health Service (NHS). Although initial problems at implementation were and must be expected, 
they went beyond what was anticipated [7-12]. As expected, clinicians were struggling with the new system. Whereas the system held the promise of streamlining patient pathways, administrative tasks that had been previously performed by clerks were now to be performed by the doctor on the computer in the same patient session (i.e. printing of results, ordering of investigations, booking of surgeries etc.). In consequence, paper notes holding pre-CRS information were left incomplete and often in disorder. Finding information in these became an additional time factor.

After we had waited four months thinking this to be enough time to overcome teething problems, we wanted to know how this new electronic system impacted on our working patterns in outpatient clinics and-more specifically - on the time actually spent with the patients.

\section{MATERIAL AND METHODS}

Before April 2008, a senior urologist in our hospital would see 20 patients in a typical clinic. As outlined above, this was in line with a national average of "overperformance" of a factor 1.4 [4] as compared to guidelines. This corresponds to 12 minutes consultation time per patient which at that time was a mixture of conversation, viewing referral letters and results, and dictation. Results were printed previously and readily sorted on top of the file. Bookings of diagnostic tests and procedures would be done by clerical staff. Because of the latter, times were deemed appropriate although an average of 12 minutes per patient could be challenging depending on the patient population. Therefore, BAUS issued its guidelines recommending no more than 15 patients per doctor per clinic $[3,4]$ in 2003.

CRS was implemented at Barts and The London NHS Trust in April 2008. Four months later, well after implementation, urological outpatient clinics were monitored as to time usage of the consulting doctors. During August 2008, medical students shadowed three senior urologists during outpatient clinics on a one-to-one basis. New referrals and follow-up patients were booked and seen at a ratio of 1:2 which corresponds to national standards $[3,4]$. Consultations were broken up and separately measured in seconds for:

1) pre-consultation computer and notes research during which the patient was kept in the waiting area (referral letters and previous correspondence from different departments for new patients, previously requested results for follow-up patients, and in case of patients suffering from urinary stone disease also booking time for an X-ray on arrival),

2) the actual consultation with the patient during which no forms or computerized requests were filled in or processed,
3) post-consultation computer and written administration (computerized bookings of investigations, admission forms etc.),

4) dictation of consultation letters.

Whenever there was a disturbance to the consultation flow (i.e. phone calls), the clock was stopped. Booking of follow-up appointments was done by the receptionists and was not considered in this study.

To avoid bias through an initial learning curve in handling CRS, the study was repeated one year after implementation of CRS in April 2009 in the same clinic, with the same personnel, using identical methodology.

The timings measured were converted into minutes (with seconds converted onto a decimal scale) and averages calculated. Results between the two study periods were compared using a student's t-test. A P-value $\leq 0.05$ was considered statistically significant.

The timings measured were then extrapolated according to a typical urologist's working pattern of 2 outpatient clinics a week $[3,4]$ and 40 working weeks per year.

\section{RESULTS}

Before April 2008, a typical outpatient clinic would see 20 patients per doctor per clinic. This meant 12 minutes total session time with each patient. The official recommendation at the time $[3,4]$ was 16 patients resulting in 15 minutes per patient. Usually, the patient would be present and interactively involved in conversation during most of this time.

In August 2008, four months after implementation of CRS, a total of 83 consultations were monitored and timed according to the criteria mentioned above. The total average consultation time for a single patient was $12.97 \pm 6.04$ minutes (range 3.13 - 28.73 minutes). Time spent with the patient was on average $5.11 \pm 2.84 \mathrm{~min}$ utes (range 0.25 - 12.8 minutes) which corresponds to $39 \%$ of the total time. Consequently, $61 \%$ were spent by the senior doctors on administrative work. $29 \%$ of patients needed an X-ray booked before seeing the doctor adding to the pre-consultation administrative time. Computer start-up with various log-in steps at the beginning of each clinic counted for 8 (!) minutes pre-consultation time for the first patient of the day.

In April 2009, one year after implementation of CRS, the study was repeated in exactly the same fashion measuring the same parameters in the same clinic. The number of consultations was comparable $(n=87) .31 \%$ of patients needed booking for a pre-consultation X-ray. The total consultation time was $15.13 \pm 8.52$ minutes (range 4 - 48.93 minutes). Of this, on average $6.94 \pm$ 5.73 minutes (range 0.71 - 29 minutes) were actually spent with the patient which corresponds to $45 \%$ of the total time. In turn, $55 \%$ of senior doctors' time was spent 
on various administrative tasks. Computer start-up times were unchanged.

When comparing the two groups, the average total time needed per patient was 14.05 minutes (range 3.13 48.93 minutes). This overall time is not much different from the 12 (actual) to 15 (recommended) minutes preCRS. Pre-consultation administrative time was stable at $4.49 \pm 3.62$ minutes (range 0 - 25.56 minutes). The consultation time spent interacting with the patient had slightly but significantly increased from $\sim 5.11$ to $\sim 6.94$ minutes $(\mathrm{p} \leq 0.05)$. For the whole group of 170 patients it was 6.05 minutes equalling $43 \%$ of time spend on a single patient. The average time for requesting investigations had slightly but significantly decreased from 2.26 to $\sim 1.48$ minutes $(\mathrm{p} \leq 0.05$ ). Dictation time had remained stable and was for all patients $\sim 1.66$ minutes. The total time spent on administration for a single patient seen in outpatients per senior urologist was $\sim 8.03$ minutes (range 0.88 - 26.27 minutes). Therewith, $57 \%$ of time was spent on administration alone.

With the average time needed per patient of $14 \mathrm{~min}$ utes, a typical outpatient clinic of one programmed activity (PA) of 4 hours can accommodate consequently no more than 16 patient per senior doctor. This corresponds with the recommendations of the British Association of Urological Surgeons BAUS [3] issued well before the arrival of any Computerized Record System.

Also, with an average of 8 minutes spent on administration, a typical senior urologist would spend $128 \mathrm{~min}-$ utes per clinic on administration, that is 2 hours and 8 minutes, or more than half of the PA.

With on average 2 clinics per week [3] over 40 working weeks per year and 8 hours work per day, our typical urologist spends 3.79 weeks $=21.3$ working days $=$ 170.66 working hours per year on administration of outpatients in clinic.

\section{DISCUSSION}

To ease outpatient clinic pressures it was thought at the start of this millennium that an electronic patient data system might be the answer [6]. The Veteran Health Administration (VHA) in the USA had successfully introduced their Computerised Patient Record System (CPRS) and introduced it as a patient-centred approach to clinical computing rather than a department-centred approach [13].

CRS was introduced at Barts and The London NHS Trust in April 2008 as one of four sites in London, and one in 12 in Southern England. British Telecom (BT) had taken over the contract with Cerner who developed the product and is due to implement 29 more sites until 2015 in England [14]. CRS means that all patient records will exist within one central database, which can be ac- cessed by the different medical bodies within the UK [15]. After implementation, there were a lot of problems in all places affected. The initial problems which would be normally expected from a project of that magnitude went well over the teething phase. Patients were lost in the system [9], and government targets were not reached $[7,9]$, which led to a snowball effect onto the referring primary care trusts [8]. Six months after implementation, Barts and The London NHS Trust still faced significant problems with data access, data recording and technical issues, leading to a $£ 3$ million revenue shortfall [9]. An independent external audit commission in another trust using CRS reported that despite 2 years of extensive remedial works since implementation they had little confidence in the data generated, found the system overly difficult and complicated and posing a significant risk to the trust's services, both in the ability to treat patients and in general administration [10].

In consequence, in February 2009 it was announced that all further CRS implementations in England were put on hold until the problems at Barts and The London NHS Trust and one other major London Hospital are fixed [11]. Following this and on the background of the worldwide credit crunch, in May 2009 Cerner announced redundancies due to a sharply reduced expected implementation rate which had been cut down from 70 to now 41 hospitals in total [14].

Whilst all this was making headlines, healthcare workers were struggling as the end-users. Generally, physicians seem to find electronic software more difficult than usual care with paperwork [16]. A one-to-onetwo-day learning curve was postulated for new users of CRS [13]. Being based on the assumption of a glitchfree system working user-friendly, this did not correspond to reality. In particular doctors were expected to research and find information that has been previously presented to them in a ready-to-use manner (referral letters, notes, printed results, X-rays), and they were also given the additional tasks of booking many investigations and other things that previously had been in the hands of nurses and clerks. They had to work with a combination of both, paper records and CRS. Paper records were left incomplete as it was assumed that new information is on CRS which could in many cases not or only with difficulty be accessed.

It turned out that some administrative processes took even longer with CRS and doctors found it impossible to use CRS to its full potential due to time restrictions and the untimely response of the system [12].

In the light of all this, we decided to look at the impact CRS had on our working pattern and, in particular, the time spent with the patients. In 1988, the time spent with the patient in a urological outpatient clinic was 7.6 
minutes on average. This decreased to 4.6 minutes in 2002 in spite of introducing time saving measures such as nurse-led clinics and one-stop clinics $40 \%$ was spent on administrative tasks [6]. In our own clinics before CRS, an average of 12 minutes total time per patient was scheduled. This on the background that most booking and researching tasks were done by administrative aides. This time was a mixture of administrative time and patient inter-action very much along the lines previously described [6]. However, the patient was involved during the whole time. We are glad to see that our study showed that the patient's time has not further reduced as compared to 2002 [6] at $\sim 6.05$ minutes as might have been expected with the additional administrative burden on the doctors. However, whereas in $200240 \%$ of doctor's time in outpatient clinics was spent in administration [6], this has now risen in our study to $57 \%$.

Out of a total of 14 minutes spent per patient, 8 minutes are spent on administration. Apart from dictation of letters, $45 \%$ of the urologist's time is nowadays spent on the computer and, more precisely, on CRS. In a similar study in the pre-CRS era, an additional 15\% disturbance time rate was calculated [6] which has not been considered in our study. This was mainly due to interruptions by phone, nurses, junior doctors and others. It also means that the expected average consultation time per patient as shown in our study would rise further by $15 \%$ from 14 to 16 minutes, and the patient number to be seen in clinic by a single doctor must therefore not exceed 15 (instead of 16). This is in accordance with the BAUS guidelines mentioned earlier [3,4] drawn up for paperadministered urological outpatient clinics in the pre-CRS era. It is of note that these baselines have not changed despite the introduction of CRS.

The time actually spend with the patient had a little but significantly risen between the two study periods from $\sim 5.11$ to $\sim 6.94$ minutes $(\mathrm{p}=0.0097)$. Nevertheless, the total administration time had not significantly changed with $\sim 8.03$ minutes $(p>0.05)$ after 4 and 12 months post-CRS. The post-consultation administration which mainly consists of booking of follow-up investigations had significantly decreased from August 2008 to April 2009 from $\sim 2.26$ to $\sim 1.48$ minutes, allowing for the additional time spent with the patient. This may indicate an increased familiarity of the doctors with CRS in bookings, however it did not have a significant impact on overall administrative time which remained increased as compared to pre-CRS assessments in comparable clinics [6].

Looking at the overall data 4 and 12 months post CRS implementation, it appears that despite extensive remedial works and increased familiarity of the users with the system not much difference has been made to the doc- tors although patients benefitted from a small increase in time spent with them.

A key message of this study lies in the average time required per patient. Data comparison with the pre-CRS era shows that CRS is not the solution to outpatient clinic overload. The BAUS recommendations from 2003 are still valid and, the clinic profile should not exceed 15 patients per doctor per clinic in urology whether working with CRS or not. We believe however, that with CRS the researching of referral data on new patients outweighs the looking up of results in follow-up patients. Therefore, at least in our clinic equal slots have been given to both groups of patients of 15 minutes each.

Another key message of this study is that an additional administrative burden has been put on the shoulders of the doctors in clinic. This does not mean administrative sessions in the office, reports, meetings and academic activities. It means simple day-to-day tasks without which an outpatient clinic and with it the doctor cannot function. It is password protected, privileged and, therefore, cannot be delegated. Extrapolating our data, a senior medical doctor consequently spends 170.66 hours or 3.7 weeks of his working life per year on administration within the outpatient clinic alone. With this price to pay, it remains to hope that CRS will fulfil its promise of a streamlined patient pathway in the long run.

\section{ACKNOWLEDGEMENTS}

We like to thank Ms. S Pararajasingam and Mr. A Ahmed for their invaluable help with collecting the data from outpatient clinics.

\section{REFERENCES}

[1] Mundy, A.R. (1998) The future of British Urology. British Journal of Urology, 82, 476-486. doi:10.1046/j.1464-410X.1998.00817.x

[2] Bromage, S.J., Napier-Hemy, R.D., Payne, S.R. and Pearce, I. (2006) Outpatient follow up appointments; Are we using the resources effectively? Postgraduate Medical Journal, 82, 465-467. doi:10.1136/pgmj.2005.043547

[3] Gilmore, P.E., Shackley, D.C., Clarke, N.W., Betts, C.D. and O'Flynn, K.J. (2005) National review of urology outpatient practice in the UK. Postgraduate Medical Journal, 81, 55-57. doi:10.1136/pgmj.2004.020693

[4] Sinclair, A.M., Derbyshire, L.F., Clarke, N.W., Betts, C.D., Shackley, D.C. and O'Flynn, K.J. (2009) National re-audit of urology outpatient practice in the UK. British Journal of Medical and Surgical Urology, 4, 160-165. doi:10.1016/j.bjmsu.2009.03.003

[5] Irvine, H. and Scott P. (1995) Consultants spend more time with each patient than in the past (letter). British Medical Journal, 311, 59. doi:10.1136/bmj.311.6996.59b

[6] Patel, H.R.H., Luxman, C.N., Bailey, T.S., Brunning, J.D.M., Zemmel, D., Morrell, L.K., Nathan, M.S. and Miller, R.A. (2002) Outpatient clinic: where is the delay? Journal of the Royal Society of Medicine, 95, 604-605. 
doi:10.1258/jrsm.95.12.604

[7] Hoeksma, J. (2008) Barts still struggling with Cerner CRS. Accessed on October 2008.

http://www.e-health-insider.com/news/4205/barts_still_st ruggling with cerner crs

[8] Collins, T. (2009) Barts responds over patients lost in NPfIT CRS system. Accessed on 29 April 2009.

http://www.computerweekly.com/blogs/tony collins/200 9/04/barts-responds-to-criticisms-i.html

[9] Barr, F. (2009) Probe into lost appointment bookings at Barts. Accessed on 26 January 2009.

http://www.e-health-insider.com/News/4509/probe into lost appointment bookings at barts

[10] Collins, T. (2008) Long-term NPfIT users lacked confidence in CRS data. Accessed on 1 December 2008. http://www.computerweekly.com/blogs/tony_collins/200 $\underline{8 / 12 / \text { trust-users-criticise-npfit-ce.html }}$

[11] Hoeksma, J. (2009) March before Royal Free fixes assessed. Accessed on 10 February 2009. http://www.e-health-insider.com/news/4563/march befor e royal free crs fixes assessed
[12] Hoeksma, J. (2008) Royal Free says Cerner "extremely challenging". Accessed on 7 August 2008.

http://www.e-health-insider.com/news/4037/royal free $\mathrm{s}$ ays cerner $\% \mathrm{E} 2 \% 80 \% 98$ extremely challenging $\% \mathrm{E} 2 \% 8$ 0\%99

[13] Protti, D.J. (2009) The benefits of a single "national" health record have been demonstrated.

http://www.connectingforhealth.nhs.uk/newsroom/world view/protti4

[14] Hoeksma, J. (2009) Cerner UK announces redundancies. Accessed on 19 May 2009.

http://www.e-health-insider.com/news/4853/cerner_uk_a nnounces redundancies

[15] (2009) Putting pharmacists at the forefront of healthcare. http://www.aah.co.uk/aah-home/pharmacy-it-solutions/li nkevolution/nhs-crs.aspx

[16] Graumlich, J.F., Novotny, N.L., Nace, G.S. and Aldag, J.C. (2009) Patient and physician perceptions after software-assisted hospital discharge: Cluster randomized trial. Journal of Hospital Medicine, 4, 356-363. 